\title{
Increased migration of colorectal cancer cells induced by TNF-alpha-treated stromal fibroblasts from human liver metastases
}

\author{
L Müller*1, J Schumacher ${ }^{1}$, B Temel ${ }^{1}$, L von Seggern² ${ }^{2}$ S Tiwari ${ }^{1}$, H Kalthoff ${ }^{1}$ \\ and DC Bröring ${ }^{1}$
}

\begin{abstract}
Address: ${ }^{1}$ University Hospital Schleswig-Holstein, Campus Kiel, Molecular Oncology, General and Thoracic Surgery, Kiel, Germany and 2University Hospital Hamburg-Eppendorf, Department of Hepatobiliary Surgery and Solid Organ Transplantation, Hamburg, Germany

* Corresponding author
\end{abstract}

from 12th Joint Meeting of the Signal Transduction Society (STS). Signal Transduction: Receptors, Mediators and Genes

Weimar, Germany. 29-31 October 2008

Published: 26 February 2009

Cell Communication and Signaling 2009, 7(Suppl I):A102 doi:I0.1I86/I478-8IIX-7-SI-A 02

This abstract is available from: http://www.biosignaling.com/content/7/SI/AI02

(c) 2009 Müller et al; licensee BioMed Central Ltd.

\section{Background}

Inflammation plays key roles in invasion, angiogenesis and metastasis. Given the multifaceted roles of tumornecrosis-factor-alpha (TNF-alpha) in these processes, its effects on the stromal fibroblasts that constitute the desmoplastic stroma in colorectal metastases are of interest.

\section{Methods}

Primary cultures of cancer-associated stromal fibroblasts (CAFs) were generated from human tissues harvested during hepatic resection. TNF-alpha expression in tissue was examined by immunohistochemistry. Activation of nuclear-factor-kappaB (NF-kappaB) activity was measured by gel mobility shift assay. The effect of TNF-alpha on migratory capacity and gene expression of CAFs was tested in presence/absence of parthenolide, an herbal inhibitor of NF-kappaB. Gene expression in tissues and cell cultures was examined by Northern blot analysis. Protein measurements in the cell culture supernatant were performed with cytometric capture beads.

\section{Results}

The colorectal metastases display immunoreactivity for TNF-alpha in tumor cells and leukocyte cells, whereas stromal fibroblasts are negative. To investigate transcriptional effects of TNF-alpha on CAFs, we analysed the expression of potential inflammatory target genes that are involved in tumor progression. CAFs that were exposed for 24 hours to TNF-alpha $(10 \mathrm{ng} / \mathrm{ml})$ showed a dramatic increased expression of interleukin-6 (IL-6), monocytechemotactic protein-1 (MCP-1) and intercellular cell adhesion molecule-1 (ICAM-1). Increasing concentrations of parthenolide $(1,5,10$ microM) dose-dependently inhibited the activation of NF-kappaB by TNF-alpha exposure for $30 \mathrm{~min}$, as well as the TNF-alpha effect on IL-6 and MCP-1 mRNA and protein expression. Exposure of CAFs with TNF-alpha significantly increased the chemotaxis of HT29 colon carcinoma cells towards these cells in a coculture migration chamber system. This migratory effect activated by paracrine TNF-alpha was inhibited by co-incubation with parthenolide.

\section{Conclusion}

CAFs are an important target for inflammatory signaling mediated by TNF-alpha/NF-kappaB in the context of tumor-stroma interaction and may play an important role in metastasis progression. Our results suggest that the inhibition of NF-kappaB activation may be an interesting strategy in antitumor therapy targeting hepatic colorectal carcinoma metastatis. 